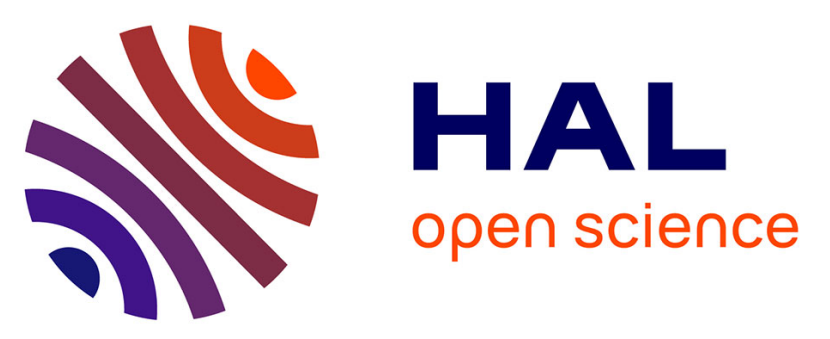

\title{
Vitamin D and parathormone levels of late-preterm formula fed infants during the first year of life
}

Vasileios Giapros, Vasiliki Schiza, Anna Challa, Vasileios Cholevas, Paraskevi

Theocharis, Georgios Kolios, Constantina Pantou, Styliani Andronikou

\section{- To cite this version:}

Vasileios Giapros, Vasiliki Schiza, Anna Challa, Vasileios Cholevas, Paraskevi Theocharis, et al.. Vitamin D and parathormone levels of late-preterm formula fed infants during the first year of life. European Journal of Clinical Nutrition, 2011, 10.1038/ejcn.2011.158 . hal-00676999

\section{HAL Id: hal-00676999 \\ https://hal.science/hal-00676999}

Submitted on 7 Mar 2012

HAL is a multi-disciplinary open access archive for the deposit and dissemination of scientific research documents, whether they are published or not. The documents may come from teaching and research institutions in France or abroad, or from public or private research centers.
L'archive ouverte pluridisciplinaire HAL, est destinée au dépôt et à la diffusion de documents scientifiques de niveau recherche, publiés ou non, émanant des établissements d'enseignement et de recherche français ou étrangers, des laboratoires publics ou privés. 
1 Vitamin D and parathormone levels of late-preterm formula

2 fed infants during the first year of life

3

4 SHORT TITLE: Vitamin D in large -preterm formula fed infants

5

6 Vasileios I. Giapros, MD ${ }^{1}$, Vasiliki Schiza ${ }^{1}$, Anna S. Challa, $\mathrm{PhD}^{2}$, Vasileios K.

7 Cholevas, $\mathrm{PhD}^{2}$, Paraskevi D. Theocharis MD, Georgios Kolios $\mathrm{PhD}^{3}$, Constantina

8 Pantou MD, Styliani K. Andronikou MD ${ }^{1}$

9

$10{ }^{1}$ Neonatal Intensive Care Unit, ${ }^{2}$ Pediatric Research Laboratory, ${ }^{3}$ Biochemistry

11 Department, University of Ioannina, Greece

\title{
Address Correspondence to:
}

Vasileios Giapros, University Hospital of Ioannina, P.O. Box 1186, Ioannina 451 10, Greece Tel: \#302651007544 FAX: \#302651007038 email:vgiapros@cc.uoi.gr

\begin{abstract}
Abbreviations: 25(OH)D: vitamin D, PTH: parathormone, BW: birth weight, CHL: crown
\end{abstract} to heel length, ALP: alkaline phosphate

Conflict of Interest statement.

NONE

(1)
16 


\section{ABSTRACT}

Objective: Preterm infants are at risk for low vitamin D but documentation on latepreterm infants is sparse. This prospective study monitored longitudinally vitamin D and parathormone $(\mathrm{PTH})$ levels in late-preterm, formula fed infants during the first year of life, taking into consideration in-utero and postnatal growth, season and diet. Population and methods: The study population comprised 128 infants of gestational age (GA) 32-36 weeks; 102 were appropriate (AGA) and 26 small for GA (SGA). Serum levels of vitamin D [25(OH)D], PTH calcium $(\mathrm{Ca})$, phosphate $(\mathrm{P})$ and alkaline phosphate (ALP) were estimated at 2 and 6 weeks and at 3,6,9 and 12 months of age. Results: The 25(OH)D levels were relatively low at 2 and 6 weeks in both AGA and SGA infants $(21 \pm 11,20 \pm 7 \mathrm{ng} / \mathrm{ml}$ and $25 \pm 16,23 \pm 8 \mathrm{ng} / \mathrm{ml}$ respectively), but increased at 6 months $(45 \pm 14,47 \pm 10 \mathrm{ng} / \mathrm{ml})$ and remained stable thereafter. SGA infants had lower 25(OH)D levels at 9 and 12 months (AGA $45 \pm 14,47 \pm 18 \mathrm{ng} / \mathrm{ml}$ vs SGA $38 \pm 13$, $37 \pm 13 \mathrm{ng} / \mathrm{ml}, \mathrm{p}<0.05) . \quad 25(\mathrm{OH}) \mathrm{D}$ deficiency $(<20 \mathrm{ng} / \mathrm{ml})$ was found in $18.5 \%$ of measurements in $92(72 \%)$ infants and $25(\mathrm{OH}) \mathrm{D}$ insufficiency $(20-32 \mathrm{ng} / \mathrm{ml})$ in $29.2 \%$ of measurements in 99 (77.3\%) infants. Most measurements with vitamin $\mathrm{D}<32 \mathrm{ng} / \mathrm{ml}$ were observed at the first 3 study points, where PTH showed an inverse association with $25(\mathrm{OH}) \mathrm{D}$, reaching a plateau thereafter. Conclusion: Late-preterm, formula fed infants may have suboptimal vitamin D levels and elevated PTH, especially during the first 3 months. Those born SGA may have lower vitamin D levels up to the end of the first year of life.

Keywords: vitamin D, parathormone, late-preterm infant, small-for-gestational age, catch-up growth 
INTRODUCTION

Most of the studies on vitamin D status in infants have focused on full-term, exclusively breastfed infants and the American Academy of Pediatrics (AAP) has recently increased the recommended vitamin $\mathrm{D}$ daily dose for breast-fed infants, aiming to ensure vitamin D levels of above $20 \mathrm{ng} / \mathrm{ml}$ (Challa et al., 2005; Specker et al., 1985; Ala-Houhala, 1985; Ziegler et al., 2006; Wagner and Greer, 2008). Other studies have investigated preterm infants with gestational age $(\mathrm{GA})<32$ weeks (or birth weight $<1800 \mathrm{~g}$ ), which are regarded to be at higher risk for vitamin $\mathrm{D}$ deficiency (Henriksen et al., 2006; Delvin et al., 2005; Lévy et al., 2005; Backström et al., 1999; Koo et al., 1995; Koletzko et al., 2005). In contrast, studies of larger preterm infants, with GA 32-36 weeks, have been few, although these infants comprise more than $9 \%$ of the entire neonatal population $(377,000$ births in the USA in 2005) and about $70 \%$ of all premature deliveries, with an increasing trend over recent years (Engle et al., 2007). These infants may have different nutritional needs from either full term infants or preterm infants of lower GA. Only recently have research efforts turned to this large neonatal group which appears to be susceptible to a variety of adverse perinatal and long term outcomes (Engle et al., 2007; Petrini et al., 2009).

Another neonatal population at risk is that of small for gestational age (SGA) neonates who are deprived in-utero of adequate nutrient supply. The accelerated growth pattern after birth (catch-up) experienced by most SGA infants may further increase their nutritional needs and deplete their vitamin D stores. One recent clinical trial examined the effects of vitamin D supplementation in SGA breastfed Indian infants (Kumar et al., 2011). To the best of our knowledge no studies have examined 
the adequacy of vitamin D status in late-preterm appropriate for gestational age (AGA) or SGA formula fed infants during the first year of life.

This prospective study aimed to monitor longitudinally the vitamin D levels in preterm, formula fed infants of 32-36 weeks GA during the first year of life, taking into consideration in-utero and postnatal growth patterns.

\section{PATIENTS AND METHODS}

This prospective study took place in the University Hospital of Ioannina, the regional hospital that accommodates the majority of deliveries $(85 \%)$ in a welldefined area in Northwest Greece. It aimed to include all the formula fed preterm infants born in the hospital at between 32 and 36 weeks GA during a two-year period (2004-2006) and subsequently followed up in the neonatal outpatient clinic. The main outcome variable was serum vitamin D and additional variables were PTH and ALP. Birth weight, catch-up growth velocity, season and diet were the surrounding factors.

Prior to enrolment of the infants, the aim of the study was explained to the parents and their written informed consent was obtained. The study was approved by the Scientific Ethical Committee of the University Hospital of Ioannina.

All preterm neonates in this hospital are monitored up to at least the second year of life. For the first year of life appointments are scheduled at the chronological age of 2 and 6 weeks, and 3, 6, 9 and 12 months, which were accordingly also designated as study points for this project. Infants with congenital anomalies or chronic diseases and those with follow up of less than 12 months were excluded from the study. All the infants studied were of Greek descent. Details of the antenatal and postnatal history along with information about maternal vitamin and mineral 
supplementation during pregnancy were recorded. The GA was estimated from early antenatal ultrasonography (US) (12-16 weeks of gestation). Children with BW below the $10^{\text {th }}$ percentile on the Alexander growth charts were classified as SGA (Alexander et al., 1999). Feeding information, whether breast milk, formula or a combination, the timing of introduction of solid foods and their type, the possible supplementary vitamins administration was collected at each study point for all infants. The milk formulas used were specified for fullterm infants because, following the current protocol of the Neonatal Unit, special transitional preterm formulas are given only to neonates with $\mathrm{GA}<32$ weeks or $\mathrm{BW}<1500 \mathrm{~g}$. The vitamin $\mathrm{D}$ content of the formulas used by the study population, as reported by the manufacturers, varied between 400 and 600IU per milk liter for the early infancy formulas (0-6 months) and was 600IU per milk liter for the late infancy formulas (6-12 months). Vitamin D enriched infant cereal and fruit preparations given in the latter period contained 100-120 IU vitamin D per serving. For purposes of analysis, summer season was regarded as the period May to October and winter as November to April.

Body weight, $\mathrm{CHL}$ and $\mathrm{HC}$ were examined at each study point, using standard techniques, by two of the authors (SA,VS). Postnatal growth velocity was estimated as the difference in weight (in grams) or height (in $\mathrm{cm}$ ) between two study points divided by the time elapsed in days. At each follow-up appointment routine morning venepuncture is performed, according to the standard hospital protocol for follow-up of preterm infants, for estimation of metabolic and nutritional parameters [blood count, ferritin, calcium $(\mathrm{Ca})$, phosphate $(\mathrm{P})$, alkaline phosphate (ALP)]. At this routine venepuncture extra blood was collected from the study infants for the measurement of serum 25(OH)D and parathormone $(\mathrm{PTH})$. Serum 25(OH)D was determined by an 
enzyme-immunoassay (EIA) method using the kit by IDS Systems Ltd, UK. The sensitivity of the method was $2 \mathrm{ng} / \mathrm{ml}$. The intra- and inter-assay CVs were $5.3 \%$ and $4.6 \%$ respectively. The biologically intact molecule of PTH (iPTH) was measured by a two-site enzyme linked immunosorbent assay (ELISA) using the kit by BIOMERICA Inc (USA). The sensitivity of the method was $0.9 \mathrm{pg} / \mathrm{ml}$. The intra- and inter-assay CVs were $3.2 \%$ and $7.7 \%$ respectively. The sample required for each determination for either assay was $25 \mu \mathrm{l}$. ALP activity, total $\mathrm{Ca}$ and inorganic $\mathrm{P}$ levels were determined on Beckman-Coulter AU 2700/5400 biochemistry analyzers. An upper normal range of ALP: 570IU/L was used for infants.

\section{Statistical Analysis}

Differences in biochemical parameters among the six study points and between subgroups were evaluated using repeated measures analysis of variance (ANOVA). When this analysis yielded significant results it was followed by simple ANOVA followed by the Fisher's PLSD test. Simple and multiple regression analyses were performed at each study point to investigate the association between $25(\mathrm{OH}) \mathrm{D}$ level and the other variables, specifically, PTH, Ca, P, ALP, season (summer or winter period), gender, BW, GA, and postnatal growth velocity in either height or weight. Logistic regression analysis was used to examined the relationship of vitamin D with variables that are by nature non continuous. For purposes of logistic regression, 25(OH)D values were grouped into quintiles and the first quintile was correlated with the other parameters in a binary manner. Values are expressed as mean plus/minus standard deviation (SD). Logarithmic transformation was made for parameters that did not show normal distribution. A level of significance of $p<0.05$ was set. It was estimated that a sample size of 128 children was sufficient to 
151

152

153

154

155

156

157

158

159

160

161

162

163

164

165

166

167

168

169

170

171

172

173

174

demonstrate a $20 \%$ difference in all the parameters examined, with a power $>80 \%$ at a significance level of 0.05 (Altman,1991). In this estimation the documented dropout trends on follow up and the cases where samples would be unsuitable for evaluation were taken into consideration.

\section{RESULTS}

A total of 216 infants with 32-36 weeks GA were eligible for the study, of which were 48 excluded; for 43 infants, the parents were unable to keep most of the 6 follow-up appointments during the study period or were unwilling to continue followup and for 5 the laboratory data collected were inadequate. Also excluded from the study were a further 40 infants, 14 of which were exclusively breastfed and 26 partially breastfed, because it was difficult to quantify the average proportion of breast milk and formula. The characteristics of the non participating infants did not differ otherwise from those of the study group. The participating infants were all formula fed during the first six months of life. Among them 102 were classified as AGA and 26 as SGA. The characteristics of the study neonates are depicted in Table 1. The majority of the infants (79\%) were fed milk formulas containing vitamin D 480 IU per liter during the first 6 months. Only 5 neonates $(3.9 \%)$ received a transitional formula containing vitamin D 980 IU per liter for a 3 month period because of $\mathrm{BW}<1500 \mathrm{~g}$. For all infants, solid food was introduced after the $5^{\text {th }}$ month of age, based on the standard infant nutrition protocols, and no major deviation was reported by the parents. According to parental reporting no study infant received a supplement of vitamin D during the study period. No differences between AGA and SGA infants were reported regarding the type or duration of formula feeding or the time of 
introduction and type of solid foods. Formula milk consumption was reported to be higher than $1000 \mathrm{ml} / \mathrm{d}$ at 3 and 6 months for all study infants. At 9 and 12 months it was higher than $600 \mathrm{ml} / \mathrm{d}$ in all infants, including the milk used in preparing foods. Milk intake did not differ between AGA and SGA groups at any study point. Two feedings of vitamin D enriched cereal or fruit baby foods (100-120 IU vitamin D per serving) were given in the later period to the majority (92\%) of the infants, and with the exception of egg yolk no other food containing vitamin D was identified in their diet. All the mothers had received $\mathrm{Ca}$ but no mother had received vitamin $\mathrm{D}$ supplement throughout pregnancy. Although no deliberate exposure of the infants to sun was reported by any parent, as they are advised to avoid direct sunlight during the first year of life, seasonality was taken into consideration.

A total number of 650 measurements in 128 infants were made (mean 5.1 measurements per infant) over the 6 time points. No statistically significant differences in vitamin D level according to season (summer or winter) were observed except for the first study period (Table 2), and thus the serum parameters of AGA and SGA infants are depicted in Table 3 independent of season.

The levels of 25(OH)D in AGA infants were lower at the 2 and 6 weeks study points and increased significantly thereafter (Table 3 ). At the 6 months study point the mean 25(OH)D level was double the levels at 2 and 6 weeks and remained stable up to 12 months. The SGA infants followed a similar pattern, but at the 9 and 12 months study points their mean $25(\mathrm{OH}) \mathrm{D}$ levels were lower than those of the AGA children (Table 3). This difference was independent of GA, body weight, season and gender. Based on recent data from adult and pediatric populations (Hathcock et al., 2007; Holick, 2007; El-Hajj Fuleihan et al., 2006; Vieth et al., 2007; Agostoni et al., 
2010; Weng et al., 2007; Willis et al., 2007; Chapuy et al., 1997; Kinyamu et al.,1998; Heaney, 2004; Harkness et al., 2005;) there is a general consensus to increase the reference values of vitamin D in infants and children (18 Vieth et al., 2007; Agostoni et al., 2010). The levels of $20 \mathrm{ng} / \mathrm{ml}$ and $32 \mathrm{ng} / \mathrm{ml}$, respectively, were applied as cutoff values for vitamin D deficiency and insufficiency for this study. Using the cutoff of $20 \mathrm{ng} / \mathrm{ml}$, over the study period $120(18.5 \%)$ of vitamin D measurements were low, in 92 (72\%) infants. Vitamin D insufficiency (20- $32 \mathrm{ng} / \mathrm{ml})$ was observed in a further $190(29.2 \%)$ measurements in $99(77.3 \%)$ infants, on a mean of 2 occasions. Most measurements of vitamin D below 32ng/ml, specifically 202 (65\%), were observed at the first 2 study points (i.e., at 2 and 6 weeks of life). From $3^{\text {rd }}$ month onwards, $35 \%$ of measurements (108) were below $32 \mathrm{ng} / \mathrm{ml}$ and between 6 and 12 months of age 18.4\% (57) (Figure 1). No infant had a level of 25(OH)D below $20 \mathrm{ng} / \mathrm{ml}$ for more than two consecutive points during the study period. SGA children had levels of $25(\mathrm{OH}) \mathrm{D}<20 \mathrm{ng} / \mathrm{ml}$ in $21.9 \%$ measurements and $20-32 \mathrm{ng} / \mathrm{ml}$ in $34.1 \%$.

Variation in the levels of PTH during the study period exhibited a pattern inverse to that of $25(\mathrm{OH}) \mathrm{D}$, being high at the first 2 study points and decreasing thereafter (Table 3). No differences in PTH levels between SGA and AGA infants were detected. As normal PTH levels have not been defined for this age group, we considered as upper normal limit the $95^{\text {th }}$ percentile for PTH in the infants with vitamin $\mathrm{D}>32 \mathrm{ng} / \mathrm{ml}$, which was $48 \mathrm{pg} / \mathrm{ml}$. Using this criterion, 86/310 measurements $(28 \%)$ in infants with vitamin D level $<32 \mathrm{ng} / \mathrm{ml}$ showed levels of PTH above the $95^{\text {th }}$ percentile. A PTH level of above 60pg/ml (the "euparathyroid" cutoff value in older individuals) was found in 68 cases, mostly during the first 3 study periods. The 
relationship between PTH and vitamin D levels during these 3 study periods is depicted in Figure 2. PTH levels were higher than the "euparathyroid" cutoff value almost exclusively in infants with $25(\mathrm{OH}) \mathrm{D}$ below the insufficiency limit $(32 \mathrm{ng} / \mathrm{ml})$.

Levels of ALP were consistently higher in SGA infants (Table 3). Mean Ca and P levels did not differ between study points or groups and no infant had a level of $\mathrm{Ca}<8.5 \mathrm{mg} / \mathrm{dl}$ or $\mathrm{P}<5 \mathrm{mg} / \mathrm{dl}$ throughout the study period.

In regression analysis at each study point, a significant association of vitamin $\mathrm{D}$ was found with $\mathrm{Ca}$ at 2 weeks $(\mathrm{r}=0.21, \mathrm{p}=0.04), 6$ weeks $(\mathrm{r}=0.20, \mathrm{p}=0.05)$ and 3 months $(\mathrm{r}=0.19, \mathrm{p}=0.05)$, with $\operatorname{ALP}(\mathrm{r}=-0.26, \mathrm{p}=0.02)$ at 6 weeks and with $\mathrm{P}(\mathrm{r}=0.22$, $\mathrm{p}=0.02$ ) at 6 months. Among the other variables (season; summer or winter period, gender, BW, GA, and postnatal growth velocity in either height or weight), only body weight growth was inversely correlated with $25(\mathrm{OH}) \mathrm{D}$ at 2 and 6 weeks and at 6 months $(r=-0.20,-0.25,-0.24$, respectively, $\mathrm{p}<0.05)$. At the 2 weeks and 6 months study points this relationship was independent of the other examined factors: odds ratio (OR): 0.84 confidence interval $(\mathrm{CI}): 0.74-0.95$ and OR: $0.85 \mathrm{CI}: 0.76-0.97$, $\mathrm{p}<0.05$ respectively.

\section{DISCUSSION}

Recent studies have extended the significance of vitamin $\mathrm{D}$ well beyond bone health (Hypponen et al., 2001; Krause et al., 1998;, Lappe et al., 2007). Levels of 25(OH)D have been linked with other biomarkers such as PTH and indices of insulin resistance, bone mineralization and $\mathrm{Ca}$ absorption, in efforts to define the optimal serum levels (Bischoff-Ferrari et al., 2006; Viljakainen et al., 2006; Roth et al., 2005; Sichert-Hellert et al., 2006). Based on the latest information, $>30 \mathrm{ng} / \mathrm{ml}$ has 
been suggested as the optimal level of vitamin D for adults, a level associated with maximal suppression of PTH (Bischoff-Ferrari et al., 2006). There is a general consensus to increase the threshold level of circulating vitamin D in infants, as in adults, with a target value for $25(\mathrm{OH}) \mathrm{D}$ of $>32 \mathrm{ng} / \mathrm{ml}(80 \mathrm{nmol} / \mathrm{L})$ (Hathcock et al.,2007, Holick, 2007, El-Hajj Fuleihan et al.,2006, Vieth et al.,2007, Agostoni et al.,2010, Weng et al., 2007, Willis et al., 2007, Chapuy et al.,1997, Kinyamu et al., 1998, Heaney, 2004, Harkness et al.,2005). Applying the recently suggested cutoff values to the population of the present study, $72 \%$ of the infants were found to be vitamin $\mathrm{D}$ deficient on at least one occasion, and $78 \%$ were found to be vitamin $\mathrm{D}$ insufficient on a mean of 2 occasions throughout the study period, which covered the first year of life. Suboptimal vitamin D levels were documented, not only early after birth (mainly reflecting maternal levels) but throughout the study period, with $35 \%$ of low levels being observed between 3 and 12 months of age. The stability of levels after the 6 months point may be attributed mainly to the continuing consumption of fortified milk formula and cereal or fruit preparations enriched with vitamin D.

The inverse relationship between vitamin D and PTH shown in Figure 2 implies a threshold effect for 25(OH)D above which PTH remains at a lower, steadystate level. The point at which PTH reaches its nadir is around $32 \mathrm{ng} / \mathrm{mL}$, which justifies the use of this value as the cutoff point for insufficiency in this study. This phenomenon has already been observed in studies in adulthood and adolescence, with a lower PTH plateau value at around 30 ng/mL (Chapuy et al., 1997; Kinyamu et al., 1998; Heaney, 2004; Harkness et al.,2005). The present study for the first time provides support for operation of the same physiological mechanism in an infant cohort at least during the first 3 months of life, and also implies physiological consequences at vitamin D levels above $20 \mathrm{ng} / \mathrm{mL}$. PTH is the principal determinant 
272 of bone remodeling (Harkness et al., 2005) and increased levels may lead to

273 secondary hyperparathyroidism and bone mineral depletion, especially in periods of

274 accelerated bone growth as the infancy.

275 Despite breastfeeding promotion policies, most children in Greece (latitude

$27639^{0} \mathrm{~N}$ ) are not breastfed after the first few months and for their supply of vitamin D

277 they rely on the milk formulas fortified with vitamin D. Late-preterm infants are

278 usually fed with formulas specific to the needs of fullterm infants and they have not

279 been well studied for vitamin D status, probably on the assumption of adequacy of

280 vitamin D supplementation. Shorter GA and lower fat content are two factors that

281 may influence the placental supply and stores of vitamin D in this group of infants at

282 birth. The reported vitamin D content of the formulas given to the study infants is the

283 same as that of formulas currently given to full-term neonates in Europe and the USA,

284 adhering to published recommendations (Koletzko et al., 2005). ESPGHAN, in a

285 recent commentary aimed at increasing the vitamin D supply, recommends giving a

286 vitamin D supplement to formula fed preterm infants in the first months (Agostoni et

287 al., 2010). As this study demonstrated, this may also be applicable to late-preterm

288 infants, possibly on an individual basis after measurement of serum levels of

$28925(\mathrm{OH}) \mathrm{D}$. We were unable to find studies on late-preterm formula fed infants of

290 similar design with which to compare our results. Percentages of vitamin D

291 insufficiency similar to those found in the infants in the present study have been

292 demonstrated recently in children and adolescences (Weng et al., 2007; Willis et al., 293 2007).

294 A lower mean vitamin D level was found in the SGA than in the AGA infants 295 at the end of the first year, specifically at the 9 and 12 months study points. This 296 difference was independent of GA, body weight, season and other confounders. It 
297

298

299

300

301

302

303

304

305

306

307

could be attributable to the reduced trans-placental transfer of nutrients experienced by SGA infants, which may include lower vitamin D transport. Low reserves in the SGA infants because of the relative reduction of fat tissue at birth available to store vitamin D may also have played a role. A further additive factor could be the increased postnatal needs due to catch-up growth that is experienced by the SGA infants after birth. Lower vitamin D levels were recently related to insulin resistance in adults (Reis et al., 2007) and it has been shown that SGA children show evidence of insulin resistance very early after birth (Evagelidou et al., 2007, Mericq et al., 2005). These possible relationships need further studies for verification of the possible role of vitamin D in SGA populations. The higher mean ALP levels found in the SGA infants might reflect an effect on bone mass, which would imply the need for even higher vitamin D supplementation than those supplied by formula in this rapidly growing group.

A negative relationship between postnatal growth velocity and vitamin D level was shown in this study at the 3 earlier study points. Late-preterm children with accelerated postnatal growth may need closer observation for optimal vitamin D serum level, irrespective of whether they are AGA or SGA.

It is important to note that there were a number of limitations in this study. One limitation was that the information on consumption of milk and solids was collected according to parental reporting at each visit so lacked precision in calculation of dietary constituents. All the infants, however, received formula milk in the recommended quantities, and no group differences were found. Ultraviolet light exposure was not included as a variable in the analysis. Although all the parents reported absence of exposure of their infants to direct sunlight, and this is reflected by 
321 the similar seasonal vitamin D levels found in the infants, brief periods of exposure

322 cannot be excluded. The lack of a control group of full-term infants for comparison

323 limits the findings of this study to the late-preterm population. Finally the number of

324 SGA infants was rather small and further verification of vitamin D levels in this group

325 is needed.

326 CONCLUSIONS

327 It is concluded that late-preterm, formula fed infants may have suboptimal serum

328 levels of vitamin D during the first year of life and increased PTH levels, especially

329 during the first 3 months. Among this group, those born SGA may have lower

330 vitamin D levels at the end of the first year. Vitamin D supplementation for formula

331 fed late-preterm infants at the first months of age may be an option, possibly on an

332 individual basis after measurement of serum levels of 25(OH)D. Further studies on

333 late-preterm infants in other geographical locations are needed to confirm the findings

334 of the present study.

335

336

337

338

339

340

341

342

343

344 


\section{REFERENCES}

1. Agostoni C, Buonocore G, Carnielli VP, et al. ESPGHAN Committee on Nutrition. Enteral nutrient supply for preterm infants: commentary from the European Society of Paediatric Gastroenterology, Hepatology and Nutrition Committee on Nutrition. J Pediatr Gastroenterol Nutr 2010;50:85-91.

2. Ala-Houhala M. 25-hydroxyvitamin D levels during breastfeeding with or without maternal or infantile supplementation of vitamin D. J Pediatr Gastroenterol Nutr 1985;4:220-226

3. Alexander GR, Kogan MD, Himes JH: 1994-1996 U.S. singleton birth weight percentiles for gestational age by race, Hispanic origin, and gender. Matern Child Health J 1999; 3:225-231

4. Altman D. Practical Statistics for Medical Research. London: Chapman and Hall, 1991:456-460.

5. Backström MC, Mäki R, Kuusela AL, Sievänen H, Koivisto AM, Ikonen RS et al. Randomised controlled trial of vitamin D supplementation on bone density and biochemical indices in preterm infants. Arch Dis Child Fetal Neonatal Ed 1999;80:F161-66.

6. Bischoff-Ferrari HA, Giovannucci E, Willett WC, Dietrich T, Dawson-Hughes B. Estimation of optimal serum concentrations of 25-hydroxyvitamin D for multiple health outcomes. Am J Clin Nutr 2006;84:18-28

7. Challa A, Ntourntoufi A, Cholevas V, Bitsori M, Galanakis E, Andronikou S. Breastfeeding and vitamin D status in Greece during the first 6 months of life. Eur J Pediatr 2005 164:724-729 
8. Chapuy MC, Preziosi P, Maamer M, Arnaud S, Galan P, Hercberg S et al. Prevalence of vitamin D insufficiency in an adult normal population. Osteoporos Int 1997;7:439-443

9. Delvin EE, Salle BL, Claris O, Putet G, Hascoet JM, Desnoulez L, et al. Oral vitamin A, E and D supplementation of pre-term newborns either breast-fed or formula-fed: a 3-month longitudinal study. J Pediatr Gastroenterol Nutr 2005; 40:43-47.

10. El-Hajj Fuleihan E, Nabulsi M, Tamim H, et al. Effect of vitamin D replacement on musculoskeletal parameters in school children: a randomized controlled trial. J Clin Endocrinol Metab 2006;91:405-412

11. Engle WA, Tomashek KM, Wallman C; Committee on Fetus and Newborn, American Academy of Pediatrics. "Late-preterm" infants: a population at risk. Pediatrics 2007;120:1390-1401.

12. Evagelidou E, Giapros VI, Challa AS, Kiortsis DN, Tsatsoulis AA, Andronikou SK. Serum adiponectin levels, insulin resistance, and lipid profile in children born small for gestational age are affected by the severity of growth retardation at birth. Eur J Endocrinol 2007; 156: 271-277

13. Harkness L, Cromer B. Low levels of 25-hydroxy vitamin D are associated with elevated parathyroid hormone in healthy adolescent females. Osteoporos Int 2005;16:109-113

14. Hathcock JN, Shao A, Vieth R, Heaney RP. Risk assessment for vitamin D. Am J Clin Nutr 2007;85:6-18

15. Heaney RP. Functional indices of vitamin D status and ramifications of vitamin D deficiency Am J Clin Nutr 2004;80(suppl):1706S-1709S 
16. Henriksen C, Helland IB, Rønnestad A, Grønn M, Iversen PO, Drevon CA. Fat-soluble vitamins in breast-fed preterm and term infants Eur J Clin Nutr 2006;60:756-762.

17. Holick MF. Vitamin D deficiency. N Engl J Med 2007;357: 266-281

18. Hypponen E, Laara E, Reunanen A, Jarvelin MR, Virtanen SM. Intake of vitaminD and risk of type 1 diabetes: a birth-cohort study. Lancet 2001;358:1500-1503.

19. Specker BL, Valanis B, Hertzberg V, Edwards N, Tsang RC. Sunshine exposure and serum 25-hydroxyvitamin D concentrations in exclusively breast-fed infants. J Pediatr 1985;107: 372-376

20. Kinyamu HK, Gallagher JC, Rafferty KA, Balhorn KE. Dietary calcium and vitamin D intake in elderly women: effect on serum parathyroid hormone and vitamin D metabolites. Am J Clin Nutr 1998;67:342-48.

21. Koletzko B, Baker S, Cleghorn G et al. Global standard for the composition of infant formula: recommendations of an ESPGHAN coordinated international expert group. J Pediatr Gastroenterol Nutr 2005;41:584-599.

22. Koo WW, Krug-Wispe S, Neylan M, Succop P, Oestreich AE, Tsang RC. Effect of three levels of vitamin D intake in preterm infants receiving high mineral-containing milk. J Pediatr Gastroenterol Nutr 1995;21:182-189.

23. Krause R, Buhring M, Hopfenmuller W, Holick MF, Sharma AM. Ultraviolet B and blood pressure. Lancet 1998;352:709-710.

24. Kumar GT, Sachdev HS, Chellani H, Rehman AM, Singh V, Arora H, Filteau S. Effect of weekly vitamin D supplements on mortality, morbidity, and growth of low birthweight term infants in India up to age 6 months: randomised controlled trial. $B M J$ 2011;342: d2975. doi: 10.1136/bmj.d2975. 
25. Lappe JM, Travers-Gustafson D, Davies KM, Recker RR, Heaney RP. Vitamin D and calcium supplementation reduces cancer risk: results of a randomized trial. Am J Clin Nutr 2007;85:1586-1591.

26. Mericq V, Ong KK, Bazaes R et al. Longitudinal changes in insulin sensitivity and secretion from birth to age three years in small- and appropriate-forgestational-age children. Diabetologia 2005;48: 2609-2614

27. Petrini JR, Dias T, McCormick MC, Massolo ML, Green NS, Escobar GJ. Increased risk of adverse neurological development for late preterm infants $J$ Pediatr 2009;154:169-176.

28. Reis JP, von Mühlen D, Kritz-Silverstein D, Wingard DL, Barrett-Connor E. Vitamin D, parathormone levels, and the prevalence of metabolic syndrome in community-dwelling older adults. Diabetes Care 2007 ;30:1549-1555.

29. Roth DE, Martz P, Yeo R, Prosser C, Bell M, Jones AB. Are national vitamin D guidelines sufficient to maintain adequate blood levels in children? Can J Public Health 2005;96:443-449

30. Sichert-Hellert W, Wenz G, Kersting M. Vitamin intakes from supplements and fortified food in German children and adolescents: results from the DONALD study. J Nutr 2006; 136:1329-1333

31. Vieth R, Bischoff-Ferrari H, Boucher BJ, et al. The urgent need to recommend an intake of vitamin D that is effective. Am J Clin Nutr 2007;85:649-650

32. Viljakainen HT, Natri AM, Karkkainen MM, et al. A positive dose-response effect of vitamin D supplementation on site specific bone mineral augmentation in adolescent girls: a double- blinded randomized placebocontrolled 1-year intervention. J Bone Miner Res 2006;21:836-844 
442

443

444

445

446

447

448

449

450

451

452

453

454

455

456

457

458

459

460

461

462

463

464

33. Wagner CL, Greer FR; Section on Breastfeeding and Committee on Nutrition, American Academy of Pediatrics. Prevention of rickets and vitamin D deficiency in infants, children, and adolescents. Pediatrics 2008;122:11421152

34. Weng FL, Shults J, Leonard MB, Stallings VA, Zemel BS. Risk factors for low serum 25-hydroxyvitamin D concentrations in otherwise healthy children and adolescents. Am J Clin Nutr 2007 Jul;86:150-158.

35. Wilkins CH, Sheline YI, Roe CM, Birge SJ, Morris JC. Vitamin D deficiency is associated with low mood and worse cognitive performance in older adults. Am J Geriatr Psychiatry 2006;14:1032-1040.

36. Willis CM, Laing EM, Hall DB, Hausman DB, Lewis RD.A prospective analysis of plasma 25-hydroxyvitamin D concentrations in white and black prepubertal females in the southeastern United States. Am J Clin Nutr 2007 ;85:124-130.

37. Ziegler EE, Hollis BW, Nelson SE, Jeter JM. Vitamin D deficiency in breastfed infants in Iowa Pediatrics 2006;118: 603-610. 


\section{$467 \quad$ Figure legends}

468

469

470

471

472

473

474

475

476

477

478

479

480

481

482

483

484

485

486

487

488

489 .

FIGURE 1 Serum level of vitamin D [(25(OH)D] (box and plots) in late preterm infants $(n=128)$ during the first year of life. Horizontal lines represent the cutoff levels for vitamin D deficiency $(20 \mathrm{ng} / \mathrm{ml})$ and insufficiency $(32 \mathrm{ng} / \mathrm{ml})$

FIGURE 2 The relationship between serum levels of intact parathormone (PTH) and vitamin $\mathrm{D}[25(\mathrm{OH}) \mathrm{D}]$ level in late preterm infants $(\mathrm{n}=128)$ during the first 3 study periods ( 2 weeks $\mathrm{R}=0.23,6$ weeks $\mathrm{R}=0.20,3$ months $\mathrm{R}=0.23, \mathrm{p}<0.05$ ) (Note: A single outlier value of vitamin $\mathrm{D}: 85 \mathrm{ng} / \mathrm{ml}$ is not depicted in the ' 6 weeks of age' figure) 
492 Table 1. Characteristics of the late-preterm study infants $(n=128)$ appropriate (AGA $493 \mathrm{n}=102)$ and small for gestational age (SGA, $n=26)$

\begin{tabular}{|c|c|c|c|}
\hline Characteristics & $\operatorname{AGA}(n=102)$ & SGA $(n=26)$ & $\mathbf{P}_{495}^{494}$ \\
\hline \multicolumn{4}{|l|}{ Birth } \\
\hline Gestational age (weeks) & $34.6 \pm 1.4$ & $34.5 \pm 1.5$ & $\mathrm{NS}^{497}$ \\
\hline Birth weight (g) & $2,371 \pm 307$ & $1,620 \pm 218$ & $0.001^{498}$ \\
\hline BW percentile & $45 \pm 17$ & $3 \pm 5$ & $\begin{array}{c}0.001 \\
500\end{array}$ \\
\hline Birth weight z-score & $-0.14 \pm 1.1$ & $-2.22 \pm 0.67$ & 0.001 \\
\hline $\mathrm{CHL}(\mathrm{cm})$ & $46.5 \pm 2.8$ & $41.6 \pm 2.3$ & $\begin{array}{c}0.001 \\
502\end{array}$ \\
\hline Head circumference $(\mathrm{cm})$ & $31.5 \pm 1.7$ & $29.8 \pm 1.8$ & $\begin{array}{r}0.001 \\
503\end{array}$ \\
\hline Gender/F (\%) & $47(46 \%)$ & $15(58 \%)$ & $\mathrm{NS}_{504}$ \\
\hline Season/summer (\%) & $58(57 \%)$ & $15(58 \%)$ & NS505 \\
\hline Admission in the NICU & $33(32 \%)$ & $16(61.5 \%)$ & 0.0506 \\
\hline Sepsis $(\%)$ & $4(3.9 \%)$ & $2(7.7 \%)$ & $\mathrm{NS}^{507}$ \\
\hline RDS 3-4grade (\%) & $2(1.96 \%)$ & $1(3.8 \%)$ & $\mathrm{NS}^{508}$ \\
\hline NEC (\%) & $2(1.96 \%)$ & $2(7.7 \%)$ & $\mathrm{NS}^{509}$ \\
\hline \multicolumn{4}{|l|}{12 months } \\
\hline Body weight (g) & $9,559 \pm 1026$ & $8,693 \pm 1094$ & $0.01_{512}$ \\
\hline $\mathrm{CHL}(\mathrm{cm})$ & $77 \pm 2.8$ & $74.4 \pm 3.9$ & $0.01 \frac{1}{513}$ \\
\hline Head circumference $(\mathrm{cm})$ & $46 \pm 1.3$ & $44.5 \pm 1.8$ & $0.0 t_{514}$ \\
\hline
\end{tabular}


520

521

522

523

524

525

526

527

528

$529 * \mathrm{p}<0.05$ between summer and winter period in AGA group
2 weeks 6 weeks 3 months 6 months 9 months 12 months

\begin{tabular}{llllllll}
\hline \hline \multirow{2}{*}{ AGA } & summer & $23 \pm 12^{*}$ & $26 \pm 16$ & $37 \pm 15$ & $45 \pm 14$ & $45 \pm 15$ & $46 \pm 16$ \\
& winter & $19 \pm 8$ & $24 \pm 9$ & $33 \pm 11$ & $45 \pm 13$ & $43 \pm 10$ & $48 \pm 15$ \\
\multirow{2}{*}{ SGA } & summer & $22 \pm 7$ & $24 \pm 7$ & $38 \pm 10$ & $49 \pm 9$ & $40 \pm 9$ & $36 \pm 6$ \\
& winter & $20 \pm 8$ & $22 \pm 8$ & $35 \pm 13$ & $46 \pm 13$ & $37 \pm 12$ & $37 \pm 7$ \\
& & & & & & \\
\hline \hline
\end{tabular}

530

531

532

533

534

535

536

537

538 
539 Table 3 Levels of serum parameters (mean values \pm SD) in late-preterm infants

540 appropriate (AGA $n=102$ ) and small for gestational age (SGA, $n=26)$ in the first year

541 of life

542

Parameter 2 weeks 6 weeks 3 months 6 months 9 months 12 months Statistics\|

\begin{tabular}{lllllllll}
\hline \hline & & & & & & & & \\
AGA & $25(\mathrm{OH}) \mathrm{D}(\mathrm{ng} / \mathrm{ml})$ & $21 \pm 11$ & $25 \pm 14$ & $35 \pm 13$ & $45 \pm 14$ & $45 \pm 14$ & $47 \pm 16$ & $\mathrm{P}<0.01$ \\
& Range & $(6-85)$ & $(4.9-53)$ & $(7.5-95)$ & $(7.7-91)$ & $(21-90)$ & $(19-91)$ & \\
SGA & & $20 \pm 7$ & $23 \pm 8$ & $36 \pm 12$ & $47 \pm 10$ & $38 \pm 13^{*}$ & $37 \pm 13^{*}$ & $\mathrm{P}<0.01$ \\
& Range & $(8-36)$ & $(7-47)$ & $(6-70)$ & $(19-54)$ & $(19-53)$ & $(22-57)$ & \\
AGA & $\mathrm{PTH}(\mathrm{pg} / \mathrm{ml})$ & $40 \pm 36$ & $42 \pm 29$ & $21 \pm 15$ & $16 \pm 12$ & $16.5 \pm 13$ & $16 \pm 15$ & $\mathbb{9 P}<0.01$ \\
SGA & & $46 \pm 40$ & $46 \pm 36$ & $20 \pm 13$ & $14 \pm 9$ & $12.9 \pm 11$ & $13 \pm 6.4$ & $\mathrm{P}<0.01$ \\
AGA & ALP (IU/L) & $273 \pm 88$ & $323 \pm 97$ & $340 \pm 199$ & $299 \pm 70$ & $283 \pm 56$ & $287 \pm 63$ & $\mathrm{~ns}$ \\
SGA & & $328 \pm 103 *$ & $370 \pm 153 *$ & $385 \pm 139 *$ & $348 \pm 95 * *$ & $393 \pm 99 * * *$ & $369 \pm 90 * * *$ & $\mathrm{~ns}$ \\
AGA & $\mathrm{Ca}(\mathrm{mg} / \mathrm{dl})$ & $10.1 \pm 0.5$ & $10.0 \pm 05$ & $10.5 \pm 04$ & $10.5 \pm 05$ & $10.5 \pm 03$ & $10.5 \pm 03$ & $\mathrm{~ns}$ \\
SGA & & $10.1 \pm 0.6$ & $10.2 \pm 0.4$ & $10.5 \pm 0.4$ & $10.5 \pm 0.4$ & $10.8 \pm 0.5$ & $10.7 \pm 0.5$ & $\mathrm{~ns}$ \\
AGA & $\mathrm{P}(\mathrm{mg} / \mathrm{dl})$ & $7.1 \pm 0.7$ & $7.0 \pm 0.5$ & $6.8 \pm 0.6$ & $6.4 \pm 0.5$ & $6.1 \pm 0.5$ & $6.0 \pm 0.5$ & $\mathrm{~ns}$ \\
SGA & & $7.0 \pm 0.8$ & $6.8 \pm 0.9$ & $6.9 \pm 0.7$ & $6.4 \pm 0.4$ & $6.3 \pm 0.4$ & $6.0 \pm 0.5$ & $\mathrm{~ns}$ \\
\hline \hline
\end{tabular}

$543 * \mathrm{p}<0.05, * * \mathrm{p}<0.01,{ }^{* * *} \mathrm{p}<0.001$ between group statistics AGA vs SGA

$544 \mathbb{2}<0.01$ denotes the overall ANOVA significance within each group

545 Within groups statistics: 25(OH)D: AGA: 2weeks vs 6weeks,p<0.05 2,6weeks vs

$5463,6,9,12$ months $\mathrm{p}<0.01$, 3months vs $6,9,12$ months $\mathrm{p}<0.05$ SGA: 2,6 weeks vs

$5473,6,9,12$ months $\mathrm{p}<0.05,3$ months vs 6 months $\mathrm{p}<0.05$. PTH: AGA: 2,6 weeks vs

$5483,6,9,12$ months $\mathrm{p}<0.01,3$ months vs $6,9,12$, months $\mathrm{p}<0.05$. SGA: 2,6 weeks vs

$5493,6,9,12$ months $\mathrm{p}<0.05,3$ months vs 9,12 , months $\mathrm{p}<0.05$ 


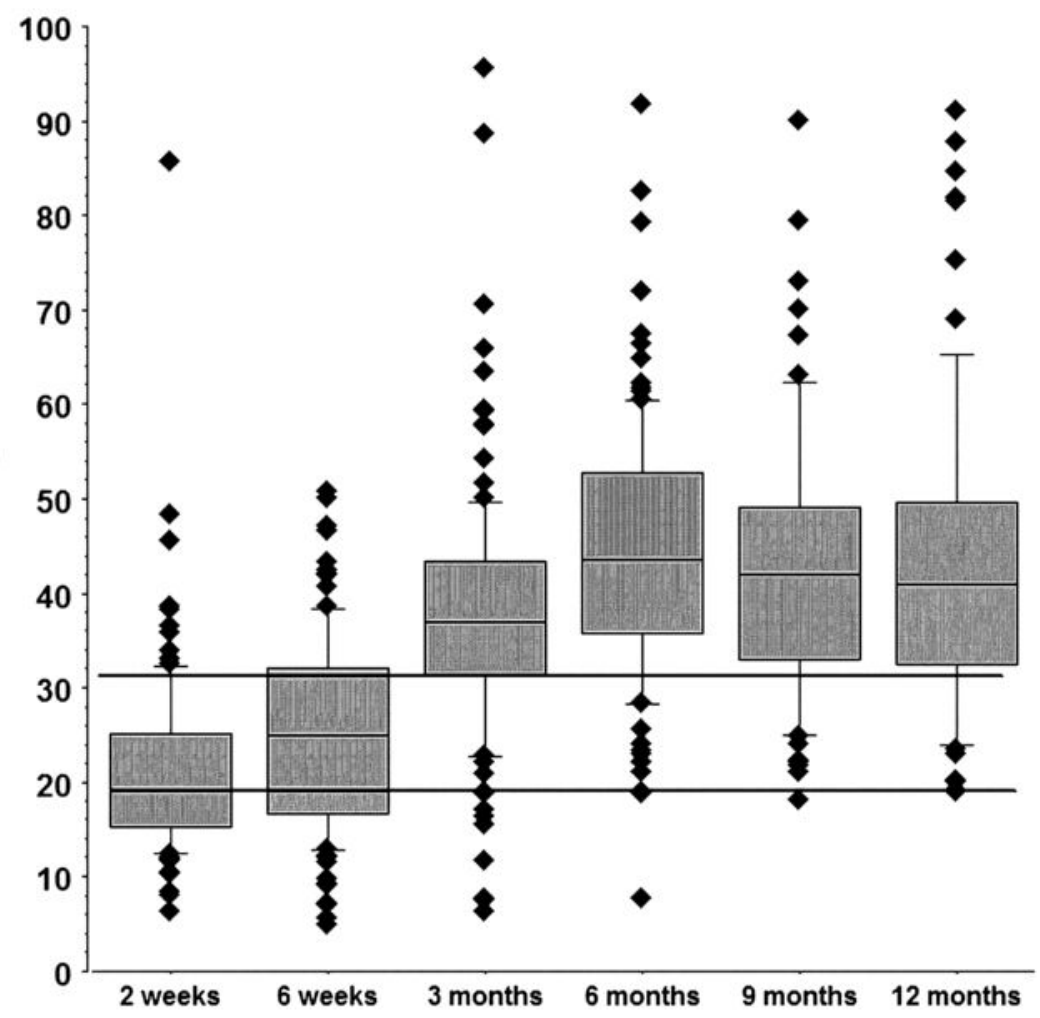



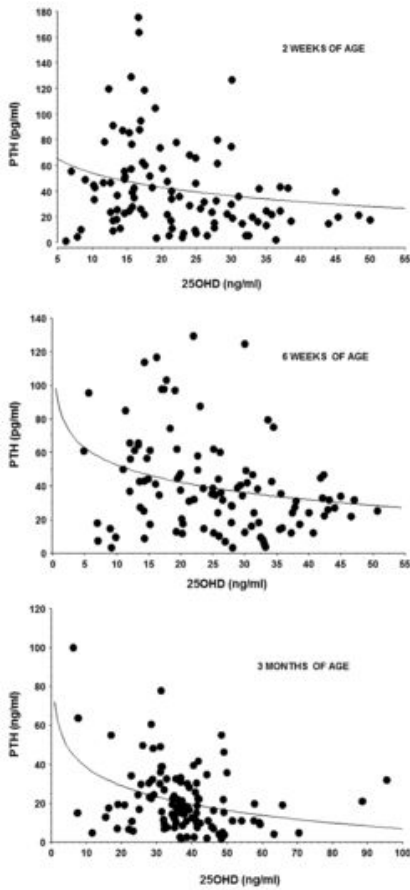